J.Lake Sci. (湖泊科学), 2016, 28(1): 217-224

DOI 10. 18307/2016. 0125

(C) 2016 by Journal of Lake Sciences

\title{
太湖不同湖区风浪的季节变化特征”
}

\author{
王 震 $^{1}$, 吴挺峰 ${ }^{2 * *}$, 邹 华 ${ }^{1 * * *}$, 贾小网 ${ }^{3}$, 黄 列 $^{4}$, 梁朝荣 ${ }^{4}$, 张志浩 $^{4}$ \\ ( 1 : 江南大学环境与土木工程学院, 无锡 214122) \\ (2: 中国科学院南京地理与湖泊研究所湖泊与环境国家重点实验室, 南京 210008) \\ (3: 江苏省水文水资源勘测局无锡分局, 无锡 214031) \\ (4:河海大学水文水资源学院,南京 210098)
}

\begin{abstract}
摘 要: 为明晰太湖风浪的空间分布及季节变化, 在湖心区设立波浪观测站,利用其记录的波浪数据证明 SWAN 模型能 够较好地模拟太湖风浪. 基于所建模型, 对 2013 年自然风场条件下太湖不同湖区风浪季节动态进行模拟分析, 结果表明: 受岸线、地形和岛屿等地理因素影响, 大太湖的风浪总是最强, 其有效波高均值为 $0.523 \mathrm{~m}$; 而东太湖风浪最小, 有效波高 均值为 $0.305 \mathrm{~m}$. 受盛行风场季节变化影响, 太湖春、夏季有效波高均值明显大于秋、冬季.太湖波浪的能量主要来源于风 场, 其有效波高随风速增大而增大,两者呈极显著正相关. 而风向则可以通过改变风区长度来影响风浪生消. 在偏东风作 用下, 太湖湖西区的风浪大于东部湖区; 而受盛行于冬季的偏北风影响, 太湖南部水域风浪要大于北部. 同时, 太湖风浪的 时空分布特征是造成太湖水质参数、沉积物和水生植物空间分布差异的重要原因之一.
\end{abstract}

关键词: 太湖分区; 风浪;季节动态;空间分布;SWAN 模型;水生植物

\section{Changes in seasonal characteristics of wind and wave in different regions of Lake Taihu}

\author{
WANG Zhen ${ }^{1}$, WU Tingfeng ${ }^{2 * *}$, ZOU Hua $^{1 * * *}$, JIA Xiaowang $^{3}$, HUANG Lie $^{4}$, LIANG Chaorong ${ }^{4}$ \& ZHANG Zhihao ${ }^{4}$ \\ (1: School of Environment and Civil Engineering, Jiangnan University, Wuxi 214122, P.R. China) \\ (2: State Key Laboratory of Lake Science and Environment, Nanjing Institute of Geography and Limnology, Chinese Academy \\ of Sciences, Nanjing 210008, P.R. China) \\ (3: Wuxi Branch of Jiangsu Province Hydrology and Water Resource Investigation Bureau, Wuxi 214031, P.R.China) \\ (4: College of Hydrology and Water Resources, Hohai University, Nanjing 210098, P.R.China)
}

\begin{abstract}
To understand the spatial and temporal distribution of wind and wave in Lake Taihu, wave observatory was set up in the center of lake. It was found that SWAN model could simulate the waves well in Lake Taihu by using the wave data recorded. Based on the calibrated model, waves of different seasons in Lake Taihu were simulated under the natural wind conditions in 2013. The results showed that due to shoreline, topography and islands, waves in the large Taihu water always showed the strongest with the mean significant wave height of $0.523 \mathrm{~m}$, while waves in east Lake Taihu were the smallest with the mean significant wave height of $0.305 \mathrm{~m}$. The values of mean significant wave height were higher in spring and summer than in autumn and winter because of seasonal changes. Wave energy in Lake Taihu was driven mainly by wind, leading to the significant wave height increased with wind speed. A significant positive correlation was found between significant wave height and wind speed. The wind direction affected growth and extinction of waves with changing the length of wind fetch. Under the easterly wind, waves in western lake was greater than that in eastern lake; while under northerly wind in winter, waves in southern lake was greater than that in northern lake. Meanwhile, the spatial and temporal distribution of waves was one of the major reasons to form a different spatial distribution of water quality, sediment and aquatic macrophytes in Lake Taihu.
\end{abstract}

* 国家水体污染控制与治理科技重大专项 (2012ZX07503-002-01) 和国家自然科学基金项目 (41230744,41471021, 41301531) 联合资助.2014-12-12 收稿;2015-05-26 收修改稿.王震( 1990 ), 男, 硕士研究生; E-mail: wzh.wz8@ 163.com.

** 通信作者;E-mail:tfwu@ niglas.ac.cn.

*** 共同通信作者;E-mail: zouhua@ jiangnan.edu.cn. 
Keywords: Partitions of Lake Taihu; wind and wave; seasonal dynamics; spatial distribution; SWAN model; aquatic macrophytes

在浅水湖泊中, 水动力扰动引起的底泥悬浮不仅导致水体透明度下降, 还可造成赋存在沉积物中的营 养盐向上覆水层释放,增加浅水湖泊富营养化的风险.平均水深 $1.9 \mathrm{~m}$ 的太湖是典型的浅水富营养化湖 泊 ${ }^{[1]}$. 该湖泊水面开阔, 水底地形平坦,多数岸线暴露在长风区条件下, 有利于风浪的生成和发展. 研究已经 证明, 太湖底泥悬浮的主要能量来自波浪 ${ }^{[2-3]}$, 湖流的作用几乎可以忽略 ${ }^{[4-5]}$. 因此, 解析太湖波浪特征对研究 其水动力过程及其生态环境效应具有重要意义.

由于风浪对太湖生态环境具有重要意义, 近年来也有不少学者对风浪开展了研究. 李一平等 ${ }^{[6]}$ 在太湖实 际波浪观测的基础上, 对太湖波浪进行数值模拟, 研究了太湖波浪的主要影响因素. 刘兴平 ${ }^{[7]}$ 研究了太湖波 浪的生消动态过程并结合湖流三维模型, 寻求太湖湖流对波浪的影响. 同时, 学者们也积极探讨太湖波浪对 生态环境的影响, 如波浪和湖流共同作用下太湖水体悬浮物输运过程 ${ }^{[8]}$, 太湖波浪与湖流对沉积物再悬浮 的影响 ${ }^{[9-11]}$, 太湖白帽覆盖率的变化与特征 ${ }^{[11]}$. 这些研究对探求太湖波浪数值模拟成果有一定意义, 但都是 在假想的定常风或较短时间内的实际风场作用下对太湖波浪的数值模拟. 而利用基于动谱平衡方程开发的 SWAN 模型, 就实际风场周年变化条件下太湖波浪时空分布的特征研究还鲜有报道.

本文基于太湖实测风场和波浪数据,通过第 3 代浅水波浪模型 SWAN, 分析 2013 年自然风场条件下太 湖不同湖区风浪时空分布特征, 并从较大的时空尺度上讨论风浪的生态环境效应, 本研究可为太湖生态环 境问题的动力学成因研究提供帮助.

\section{1 数据与方法}

\section{1 太湖概况}

太湖 ( $30^{\circ} 55^{\prime} 40^{\prime \prime} \sim 31^{\circ} 32^{\prime} 58^{\prime \prime} \mathrm{N}, 119^{\circ} 52^{\prime} 32^{\prime \prime} \sim 120^{\circ} 36^{\prime} 10^{\prime \prime} \mathrm{E}$ ) 是长江三角洲的一个大型浅水湖泊 (图 1). 太湖水域面 积 $2338 \mathrm{~km}^{2}$, 南北长 $68.5 \mathrm{~km}$, 东西平均宽 $34 \mathrm{~km}$, 最宽处 $56 \mathrm{~km}$. 太湖平均水深 $1.9 \mathrm{~m}$, 最大水深不超过 $3 \mathrm{~m}$, 其最深 处位于湖心偏西、平台山以北的区域.太湖湖面开阔, 水下地形平坦, 平均坡度只有 19.7". 按照岸线、水质和水 下地形等因素, 太湖可分为大太湖、梅梁湾、贡湖、竺山湖、胥湖、西部沿岸、南部沿岸、东太湖和箭湖东荠咀 9 个湖区 ${ }^{[12]}$ (图 1).太湖流域夏季受海陆气温差异影响, 盛行东南风; 冬季受来自西伯利亚的寒流影响, 盛行 西北风.由于全球气候变暖、城镇化等原因, 太湖的年平均风速和最大风速均呈逐年下降的趋势.

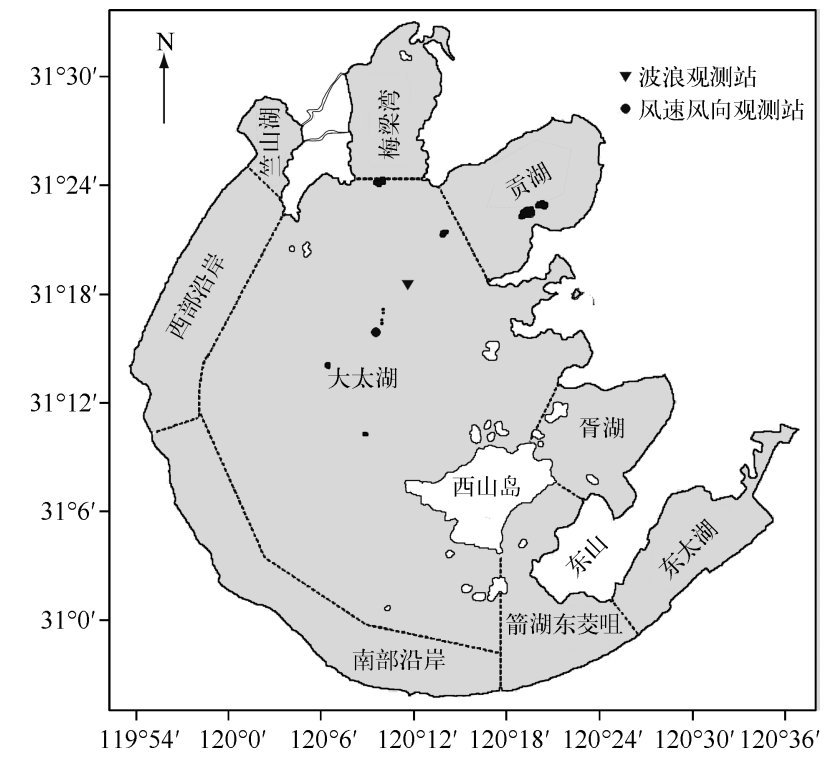

图 1 观测站及太湖分区示意

Fig. 1 Sketch of observation stations and nine regions in Lake Taihu 


\section{2 第三代浅水波浪模型}

SWAN 模型建立在波浪能量平衡方程基础上,考虑了波浪作用过程中的波浪折射、反射、浅化、破碎、白 帽、底摩擦及波一波相互作用, 其中未考虑湖流的作用和波浪绕射的影响. SWAN 模型能够很好地运用于海 岸、湖泊、河口等浅水区域,为波浪的传播以及带来的影响提供充分的依据.

1.2.1 动谱平衡方程 SWAN 模型不是以二维能谱密度而是以二维动谱密度表示随机波, 因在流场中, 动谱 密度守恒, 而能谱密度不守恒, 动谱密度与能谱密度和相对频率的关系为: $N(\sigma, \theta)=E(\sigma, \theta) / \sigma, N(\sigma, \theta)$ 随 时间、空间而变化.在笛卡尔直角坐标系下,动谱平衡方程可表示为 ${ }^{[13]}$ :

$$
\frac{\partial}{\partial t} N+\frac{\partial}{\partial x} C_{x} N+\frac{\partial}{\partial y} C_{y} N+\frac{\partial}{\partial \sigma} C_{\sigma} N+\frac{\partial}{\partial \theta} C_{\theta} N=\frac{S}{\sigma}
$$

式中,方程左边第 1 项为 $N$ 随时间的变化率; 第 $2 、 3$ 项分别表示 $N$ 在地理空间坐标 $x, y$ 方向上的传播 $\left(C_{x}\right.$ 和 $C_{y}$ 分别为 $x$ 和 $y$ 方向的传播速率); 第 4 项表示流场和水深所引起的 $N$ 在相对频率 $\sigma$ 空间的变化;第 5 项为 $N$ 在 谱分布方向 $\theta$ 空间 (谱方向分布范围) 的传播; $S$ 为以谱密度表示的源汇项,包括风能输人、波与波之间非线性 相互作用和由于底摩擦、白浪、破碎等引起的能量损耗; $C_{x} 、 C_{y} 、 C_{\sigma}$ 和 $C_{\theta}$ 分别代表在 $x 、 y 、 \sigma$ 和 $\theta$ 空间的波浪传播 速度.

1.2.2 波浪能量输入和损耗项 风能输人使用共振机制 ${ }^{[14]}$ 和反馈机制 ${ }^{[15]}$ 来描述, 相应的源函数可表示为线 性增长和指数增长两部分之和.波浪能量的耗散项主要是白浪、底部摩檫和由水深引起的波破碎. 白浪主要 由波陡度控制, 根据 Hasselmann 等提出的脉动平均模型进行计算 ${ }^{[13]}$; 底摩擦采用 Collins 拖曳理论模型; 水 深引起的波破碎基于 Miche 准则, Battjes 等 ${ }^{[16]}$ 根据大量试验数据及现场资料, 认为在浅水域, 对于不同类型 的地貌, 随机波的最大破碎波高 $H_{\mathrm{m}}$ 与水深 $d$ 的关系可表示为: $H_{\mathrm{m}}=\gamma \cdot d$.

1.2.3 波与波之间非线性相互作用 在深水域, 四相波与波非线性相互作用占主导地位, 谱能由谱峰处向低 频转移 (使得峰频变小) 和高频转移 (高频处能量由于白浪而耗散掉). 在浅水域, 三相波与波之间非线性相 互作用是主要影响因素, 能量由低频向高频处转移. 在 SWAN 模型中, 四相波一波相互作用采用 Hasselmann 等 ${ }^{[13]}$ 提出的离散相互作用近似法 (DIA) 计算, 在三相波相互作用的计算中,每个谱方向上均采用 Eldeberky 的集合三相近似模型 (LTA ${ }^{[17]}$, 它由 Eldeberky 等的离散三相近似模型 ${ }^{[18]}$ 改进而得.

1.2.4 SWAN 参数设置 SWAN 模型物理过程考虑底摩擦效应、白浪损耗和非线性波一波之间相互作用等耗 散机制. 底摩擦引起的消耗采用 Collins 模型, 底摩擦系数取 0.025 ; 破碎系数取均值 0.73 . 沿逆时针方向的谱 分布方向 $\theta$ 空间 (即谱方向分布范围) 的谱方向步长取为 $10^{\circ}$, 谱频率 $\sigma$ 计算范围为 $0.04 \sim 1.00 \mathrm{~Hz}$, 网格数为 15. 以 JONSWAP 谱和 4 阶余弦函数表示二维谱. 因人湖河道对太湖波浪的影响较小, 可忽略不计, 作陆地边 界处理. 以 $X_{10} 、 Y_{10}$ 风场作为模型风输人. 计算网格为矩形网格, 计算步长 $1 \mathrm{~km}$, 由此可将太湖划分为 $69 \times 69$ 个 网格, $x 、 y$ 方向上计算域长度均为 $69 \mathrm{~km}$. 同时,模型验证的计算时间域为 2014 年 8 月 14 日 6:10 至 8 月 17 日 $5: 40$, 计算时间步长设置为 $10 \mathrm{~min}$, 模型计算结果输出的时间间隔为 $30 \mathrm{~min}$. 模型模拟的计算时间域为 2013 年 1 月 1 日 $0: 00$ 至 12 月 31 日 $23: 30$, 计算时间步长设置为 $30 \mathrm{~min}$,模型计算结果输出的时间间隔 为 $6 \mathrm{~h}$.

\section{3 数据采集与处理}

风速、风向观测站位于太湖湖心 $\left(31^{\circ} 16^{\prime} 40^{\prime \prime} \mathrm{N}, 120^{\circ} 9^{\prime} 16^{\prime \prime} \mathrm{E}\right)$, 于 2013 年 1 月 1 日 $0: 00$ 至 2013 年 12 月 31 日 23:30 及 2014 年 8 月 14 日 6:10 至 8 月 17 日 5:40 逐时记录水面以上 $10 \mathrm{~m}$ 高度处的 $10 \mathrm{~min}$ 平均风速, 采样时间间隔 $30 \mathrm{~min}$, 全湖采用同一风场数据作为输人, 将此风场分解至笛卡尔坐标系的 $x$ 轴和 $y$ 轴, 表现 形式为 $X_{10} 、 Y_{10}$ :

$$
\begin{aligned}
& X_{10}=-\cos (W D \cdot \pi / 180) \cdot W S \\
& Y_{10}=-\sin (W D \cdot \pi / 180) \cdot W S
\end{aligned}
$$

式中, $W D$ 代表站点处的风向, $W S$ 代表站点处的风速.

波浪观测使用英国 Valeport 有限公司生产的采样频率为 $8 \mathrm{~Hz}$ 的高精度 Valeport, 观测站位于太湖湖心 $\left(31^{\circ} 18^{\prime} 33^{\prime \prime} \mathrm{N}, 120^{\circ} 12^{\prime} 22^{\prime \prime} \mathrm{E}\right)$, 于 2014 年 8 月 14 日 $6: 10$ 至 8 月 17 日 $05: 40$ 进行观测, 采样时间间隔 $30 \mathrm{~min}$, 
得到有效波高 $\left(H_{\mathrm{s}}\right)$ 及谱峰周期 $\left(T_{\mathrm{p}}\right)$ 等.

数据统计分析使用 Excel 和 SPSS 20.0 软件, 作图使用 Origin 8.1 和 Surfer 8 软件.采用 Pearson 相关分析 法表示相关性, $P<0.01$ 表示两者呈极显著相关, $P<0.05$ 表示两者呈显著相关. 使用确定性系数表示模拟值 与实测值之间的拟合程度：

$$
D C=1-\frac{\sum_{i=1}^{n}\left[y_{\mathrm{c}}(i)-y_{0}(i)\right]^{2}}{\sum_{i=1}^{n}\left[y_{0}(i)-\overline{y_{0}}\right]^{2}}
$$

式中, $D C$ 为确定性系数, $y_{0}(i)$ 为实测值, $y_{c}(i)$ 为预报值, $\overline{y_{0}}$ 为实测值的均值, $n$ 为资料序列长度.

\section{2 结果与讨论}

\section{1 模型验证}

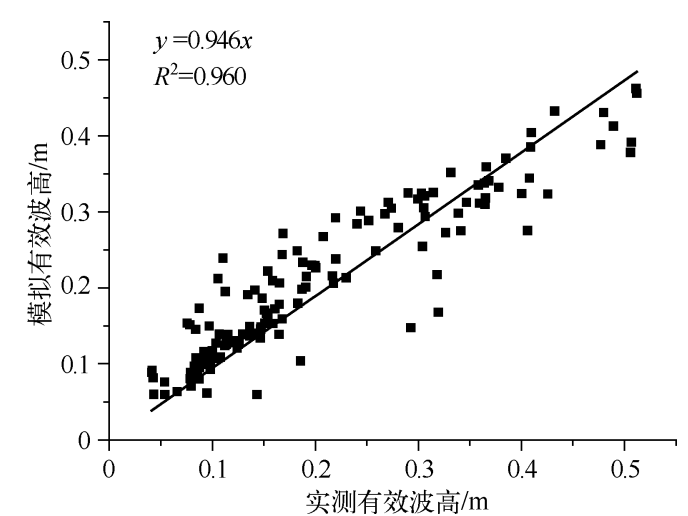

图 2 模拟与实测有效波高的线性关系

Fig.2 Linear relationship between calculated and measured values of significant wave height

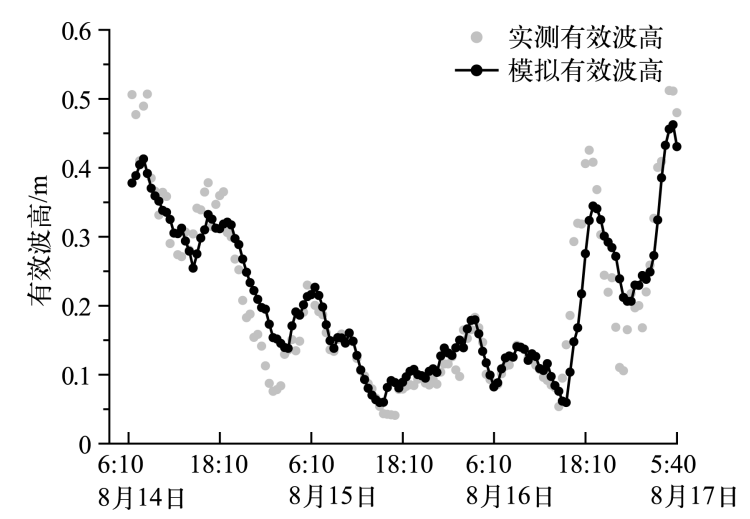

图 32014 年 8 月 14 日 6:10 至 17 日 5:40 湖心 观测站有效波高实测值与计算值的比较

Fig.3 Comparison of measured and calculated values of significant wave height in the center of Lake Taihu from August 14th 6:10 to 17 th $5: 40$ of 2014
通过建立 2014 年 8 月 14 日 $6: 10$ 至 8 月 17 日 5:40 间模拟与实测有效波高值之间的线性关 系 (图 2), 表明模拟与实测有效波高值能够紧密 分布在直线 $y=0.946 x$ 两侧, 判定系数 $R^{2}=0.960$ (样本数 $n=288$ ); 相对误差范围为 $0.03 \%$ $28.7 \%$, 均值为 $10.7 \%$; 实测值与模拟值呈极显著 正相关 $(r=0.83, P<0.01)$, 确定性系数为 0.84 . 可 见有效波高的模拟值能够较好地反映太湖波浪 的实际情况, SWAN 模型能够较好地表现太湖的 风浪特征.

验证结果表明, 模拟的有效波高与实测波高 变化趋势基本一致 (图 3), 但两者之间存在一定 的误差. 在模拟初期, 实测值与模拟值误差较大, 随着模拟时间的推移, 风浪场逐渐形成, 模拟值 与实测值越来越接近. 误差来源 ${ }^{[19]}$ 可能是: (1) 由于全湖采用的是空间均匀的逐时风场, 与 实际风场有一定的误差; (2) 在阻挡物较多的狭 长水域以及湖湾内, 以此空间均匀风场带来的误 差影响就会大些; (3) 未考虑波流相互作用; (4) 尽管风浪是太湖波浪的主要能量来源, 但是实测 波浪还包括船行波和潮汐等.

\section{2 太湖不同湖区风浪的季节分布特征}

2.2.1 2013 年太湖风场特征分析 对太湖湖心观 测站 (图 1) 记录的 2013 年风速、风向开展统计分 析. 2013 年太湖月均风速 (图 4) 在 3.0 6.0 m/s 之间, 其中春季 $(3-5$ 月)、夏季 $(6-8$ 月) 和秋 季 (9-11月) 风速相对较高, 平均约 $4.9 \mathrm{~m} / \mathrm{s}$; 冬 季( 2013 年 $1 、 2$ 和 12 月) 风速低, 为 $3.8 \mathrm{~m} / \mathrm{s}$. 2013 年太湖四季风向分布情况见表 1 , 春季和夏 季以东南风为主, 秋季以东北风为主, 冬季以西 北风为主. 依据蒲福风级分类标准, 2013 年太湖 风场序列统计情况见表 2. 2013 年太湖流域主要 
以轻风、微风、和风为主, 风速介于 $1.6 \sim 7.9 \mathrm{~m} / \mathrm{s}$. 其 中尤以微风发生频率最高, 占全年的 $31.87 \%$. 全年 观测到的最大风速为 $15.0 \mathrm{~m} / \mathrm{s}$, 达到疾风标准.

2.2.2 2013 年太湖风浪时空分布特征 基于 2013 年实测风场,利用 SWAN 模型对太湖 2013 年 1 月 1 日 $0: 00$ 至 12 月 31 日 23:30 的风浪进行模拟， 统计分析太湖风浪的时空分布特征.

2013 年 9 个湖区 12 个月的有效波高的最大值 见表 3.2013 年太湖的有效波高最大值在 0.217 $0.652 \mathrm{~m}$ 之间. 大太湖的风浪总是最强, 其有效波高 均值为 $0.523 \mathrm{~m}$; 而东太湖风浪最小, 有效波高均 值为 $0.305 \mathrm{~m}$. 有文献报道 ${ }^{[6,20]}$, 风浪的大小与风 速、风时、风区长度有着密切的关系; 另外, 风浪的 影响因子还包括水深、地形、岸线形状、沉水植物 覆盖度等. 大太湖平均水深 $2.3 \mathrm{~m}$, 水面开阔; 东太 湖平均水深仅为 $1.05 \mathrm{~m}$, 水域呈狭长型; 这两个湖



图 4 太湖湖心气象观测站记录 的 2013 年各月月平均风速变化过程

Fig.4 Changes of monthly average wind speed in 2013 recorded by meteorological station in center of Lake Taihu 区的特征有着本质区别, 东太湖的水力条件为沉水植物的生长创造了有利的环境. 事实上, 通过多年的野外 观测发现大太湖水底几乎无水草, 而东太湖水草生长茂盛.Jackson 等 ${ }^{[21]}$ 和 Hamilton 等 ${ }^{[22]}$ 研究认为水生植物 能够阻碍波浪的形成, 并降低水流速度. 因此, 水生植物能阻碍波浪的发展, 起到消浪的作用; 进而可以降低 底泥再悬浮 ${ }^{[23]}$ 和内源释放 ${ }^{[24]}$ 的可能性. 这又恰恰说明草型湖泊 (胥湖和东太湖) 的透明度和水质优于藻型 湖泊 (梅梁湾、贡湖和竺山湖 ${ }^{[25-26]}$. 太湖北部 3 个湖湾有效波高值大小顺序为: 梅梁湾>贡湖>竺山湖. 竺山 湖水域面积最小, 风吹程短, 不利于风浪的生长, 这是该湖湾有效波高小的主要原因之一. 在盛行东南风的夏 季, 西部沿岸区的有效波高值均比南部沿岸区高, 这与西部沿岸区风区长度、岸线形状规则有着密切的关系.

表 12013 年太湖湖心气象站记录的风向统计结果

Tab.1 Analysis of wind direction in 2013 recorded by meteorological station in center of Lake Taihu

\begin{tabular}{|c|c|c|c|c|c|c|c|c|}
\hline \multirow{2}{*}{ 季节 } & \multicolumn{2}{|c|}{$0^{\circ} \sim 90^{\circ}$} & \multicolumn{2}{|c|}{$90^{\circ} \sim 180^{\circ}$} & \multicolumn{2}{|c|}{$180^{\circ} \sim 270^{\circ}$} & \multicolumn{2}{|c|}{$270^{\circ} \sim 360^{\circ}$} \\
\hline & 出现次数 & 比例 & 出现次数 & 比例 & 出现次数 & 比例 & 出现次数 & 比例 \\
\hline 春季 & 991 & $22.48 \%$ & 2306 & $52.30 \%$ & 477 & $10.82 \%$ & 635 & $14.40 \%$ \\
\hline 夏季 & 764 & $17.59 \%$ & 2446 & $56.32 \%$ & 648 & $14.92 \%$ & 485 & $11.17 \%$ \\
\hline 秋季 & 1415 & $32.48 \%$ & 1239 & $28.44 \%$ & 437 & $10.03 \%$ & 1265 & $29.04 \%$ \\
\hline 冬季 & 925 & $21.39 \%$ & 1266 & $29.28 \%$ & 547 & $12.65 \%$ & 1586 & $36.68 \%$ \\
\hline
\end{tabular}

表 22013 年太湖湖心气象站记录的风速等级统计结果

Tab.2 Analysis of wind level in 2013 recorded by meteorological station in center of Lake Taihu

\begin{tabular}{ccccc}
\hline 蒲福风级 & 名称 & 风速 $/(\mathrm{m} / \mathrm{s})$ & 出现次数 & 比例 \\
\hline 0 & 无风 & $0 \sim 0.2$ & 10 & $0.06 \%$ \\
1 & 软风 & $0.3 \sim 1.5$ & 1251 & $7.46 \%$ \\
2 & 轻风 & $1.6 \sim 3.3$ & 4485 & $26.75 \%$ \\
3 & 微风 & $3.4 \sim 5.4$ & 5344 & $31.87 \%$ \\
4 & 和风 & $5.5 \sim 7.9$ & 4060 & $24.21 \%$ \\
5 & 清风 & $8.0 \sim 10.7$ & 1412 & $8.42 \%$ \\
6 & 强风 & $10.8 \sim 13.8$ & 193 & $1.15 \%$ \\
7 & 疾风 & $13.9 \sim 17.1$ & 12 & $0.07 \%$ \\
\hline
\end{tabular}

受控于风速、风向的季节波动,太湖春、夏季有效波高均值大于秋、冬季.SWAN 模拟结果表明:2013 年 
全太湖春、夏、秋和冬季有效波高平均值分别为 $0.433 、 0.444 、 0.418$ 和 $0.343 \mathrm{~m}$. 各湖区有效波高季节分布与 此相似,例如: 大太湖春、夏、秋、冬季有效波高分别为 $0.565 、 0.543 、 0.546$ 和 $0.435 \mathrm{~m}$; 东太湖春、夏、秋、冬季 有效波高分别为: $0.424 、 0.419 、 0.416$ 和 $0.329 \mathrm{~m}$. 风速是导致太湖风浪这种季节变化的主要因素. 统计分析结 果显示, 太湖有效波高与风速呈极显著正相关 $(r=0.47, P<0.01)$, 即有效波高与风速的季节变化一致, 风速 越大, 有效波高越大. 此外, 湖流 ${ }^{[27]}$ 、水位 ${ }^{[28]}$ 、行船 ${ }^{[29]}$ 及水生植物等季节变化也可能对风浪季节动态产生 影响.

表 32013 年不同湖区各月有效波高最大值 $(\mathrm{m})$

Tab.3 Monthly maximum significant wave height in 2013 in different regions of Lake Taihu

\begin{tabular}{cccccccccc}
\hline 年-月 & 大太湖 & 梅梁湾 & 贡湖 & 竺山湖 & 胥湖 & 西部沿岸 & 南部沿岸 & 东太湖 & 箭湖东茭咀 \\
\hline $2013-01$ & 0.403 & 0.330 & 0.303 & 0.275 & 0.314 & 0.331 & 0.363 & 0.242 & 0.325 \\
$2013-02$ & 0.509 & 0.451 & 0.405 & 0.344 & 0.364 & 0.483 & 0.440 & 0.309 & 0.377 \\
$2013-03$ & 0.513 & 0.425 & 0.391 & 0.320 & 0.367 & 0.397 & 0.446 & 0.303 & 0.381 \\
$2013-04$ & 0.564 & 0.474 & 0.429 & 0.377 & 0.418 & 0.444 & 0.490 & 0.324 & 0.452 \\
$2013-05$ & 0.618 & 0.505 & 0.442 & 0.392 & 0.413 & 0.502 & 0.511 & 0.340 & 0.440 \\
$2013-06$ & 0.591 & 0.572 & 0.495 & 0.435 & 0.461 & 0.570 & 0.531 & 0.370 & 0.478 \\
$2013-07$ & 0.551 & 0.495 & 0.415 & 0.371 & 0.393 & 0.492 & 0.464 & 0.326 & 0.407 \\
$2013-08$ & 0.488 & 0.454 & 0.384 & 0.351 & 0.351 & 0.456 & 0.430 & 0.293 & 0.373 \\
$2013-09$ & 0.457 & 0.386 & 0.344 & 0.312 & 0.345 & 0.359 & 0.414 & 0.273 & 0.362 \\
$2013-10$ & 0.531 & 0.449 & 0.401 & 0.356 & 0.389 & 0.419 & 0.461 & 0.312 & 0.405 \\
$2013-11$ & 0.652 & 0.520 & 0.474 & 0.428 & 0.456 & 0.445 & 0.509 & 0.350 & 0.480 \\
$2013-12$ & 0.394 & 0.355 & 0.284 & 0.258 & 0.268 & 0.331 & 0.294 & 0.217 & 0.285 \\
\hline
\end{tabular}

\section{3 典型风向下微风引起的波浪季节分布特征}

由于 2013 年太湖盛行微风, 因此借助所建 SWAN 模型分析微风风速条件下西南、东南、东北和西北风 在太湖形成的风浪空间分布. 在西南风作用下, 波高由西南沿岸向湖心逐渐变大, 绕过西山岛, 在梅梁湾和贡 湖口达到最大 (图 5A). 在夏季盛行的东南风作用下, 波高由箭湖东荠咀一南部沿岸一湖心逐渐变大, 在梅梁 湖口以西的湖心区域达到最大 (图 5B). 在东北风作用下, 波高最大值在西部沿岸附近的湖心区域, 其次为大 太湖和西部沿岸, 各湖湾的有效波高基本在 0.15 0.18 m(图 5C). 而西北风引起的风浪的有效波高值则由西 北沿岸区向湖心逐渐增大, 西山岛附近达到最大; 在西山岛的阻碍作用下, 胥湖和东太湖的波高明显减小 (图 5D).

风向可以通过改变风区长度来影响风浪生消. 不过, 不论何种风向下, 大太湖的有效波高始终最大, 在 0.16 0.22 m 之间. 而该湖区也是太湖水动力扰动最为频繁和剧烈的区域. 沈吉等 ${ }^{[30]}$ 观测到湖心大部分湖底 露出黄褐色硬质黄土层, 局部地区有小于 $3 \mathrm{~cm}$ 的上覆浮泥, 这可能与该区域始终频繁遭受强风浪扰动有关. 东太湖和胥湖的有效波高都是最小的, 在 $0.10 \sim 0.16 \mathrm{~m}$ 之间 (图 5). 这两块水域相对封闭, 风区长度较小, 不 利于风浪的成长和发展. 这样的水动力条件大大降低了沉水植物的机械损伤, 为沉水植物的生长提供了良好 的环境; 同时,而沉水植物繁盛又可以起到消浪的作用,两者间存在着正反馈机制.

\section{3 结论}

1) 通过 2014 年 8 月 14 日 $6: 10$ 至 8 月 17 日 5:40 实测有效波高与模拟有效波高比较发现,其变化趋势 基本一致, 能够紧密分布在直线 $y=0.946 x$ 两侧, 判定系数 $R^{2}=0.960$ (样本数 $n=288$ ); 相对误差范围为 $0.03 \% \sim 28.7 \%$, 均值为 $10.7 \%$; 实测值与模拟值呈极显著正相关 $(r=0.83, P<0.01)$, 确定性系数为 0.84 . 可见 SWAN 模型能够较好地体现太湖风浪特征.

2) 受岸线、地形和岛屿等地理因素影响, 2013 年大太湖的风浪总是最强的, 其有效波高均值为 $0.523 \mathrm{~m}$; 而东太湖风浪最小, 有效波高均值为 $0.305 \mathrm{~m}$. 受盛行风场季节变化影响, 太湖春、夏季有效波高均值明显大于 秋、冬季.太湖波浪的能量主要来源于风场, 其有效波高随风速增大, 两者呈极显著正相关 $(r=0.47, P<0.01)$. 

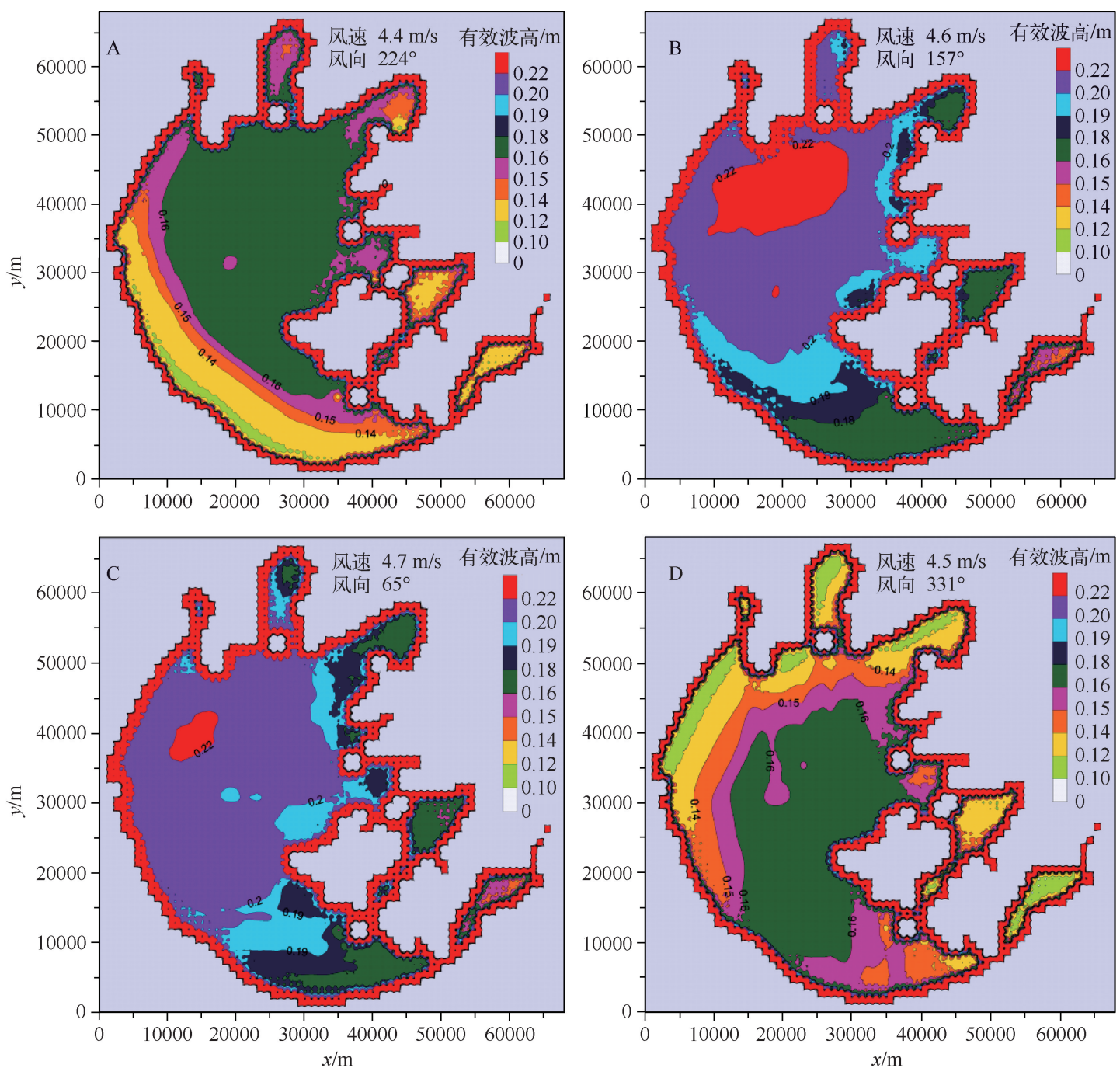

图 52013 年典型风向下微风引起的太湖有效波高的季节分布

Fig.5 Seasonal distribution of significant wave height in Lake Taihu under different wind directions in 2013

3) 风向可以通过改变风区长度来影响风浪生消. 在偏东风作用下, 太湖湖西区的风浪大于东部湖区; 而 受盛行于冬季的偏北风影响, 太湖南部水域风浪要大于北部. 同时, 太湖风浪的时空分布特征是造成太湖水 质参数、沉积物和水生植物空间分布差异的重要原因之一.

\section{4 参考文献}

[ 1 ] 孙顺才, 黄渏平. 太湖. 北京: 海洋出版社, 1993 .

[ 2 ] 秦伯强, 胡维平, 高 光等. 太湖沉积物悬浮的动力机制及内源释放的概念性模式. 科学通报, 2003, 48(17): 1822-1831.

[ 3 ] Wu TF, Qin BQ, Zhu GW et al. Modeling of turbidity dynamics caused by wind-induced waves and current in the Taihu Lake. International Journal of Sediment Research, 2013, 28(2) : 139-148.

[ 4 ] Jin KR, Ji ZG. Calibration and verification of a spectral wind-wave model for Lake Okeechobee. Ocean Engineering, 2001, 28(5): 571-584. 
[ 5 ] Bailey MC, Hamilton DP. Wind induced sediment resuspension: a lake-wide model. Ecological Modeling, 1997, 99(2): 217-228.

[6] 李一平, 逢 勇, 刘兴平等. 太湖波浪数值模拟. 湖泊科学, 2008, 20(1) : 117-122. DOI 10. 18307/2008. 0118.

[ 7 ] 刘兴平. 太湖波浪过程的数值模拟. 江苏大学学报: 自然科学版, 2009, 30(1):80-85.

[ 8 ] 李一平, 逢 勇, 罗潋苾. 波流作用下太湖水体悬浮物输运实验及模拟. 水科学进展, 2009, 20(5) : 701-706.

[9] 罗潋苾, 秦伯强. 太湖波浪与湖流对沉积物再悬浮不同影响的研究. 水文, 2003, 23(3): 1-4.

[10］汤露露，王 鹏，姚 琪. 太湖湖流、波浪、沉积物的三维数值模拟. 水资源保护, 2011, 27(2): 1-5.

[11] 陶蓉茵. 不同风场条件下太湖波浪数值模拟的研究及其应用 [学位论文]. 南京: 南京信息工程大学, 2012.

[12] 刘聚涛, 高俊峰, 姜加虎等. 基于突变理论的太湖蓝藻水华危险性分区评价. 湖泊科学, 2010, 22(4): 488-494. DOI 10. 18307/2010. 0403.

[13] Hasselmann S, Hasselmann K, Allender JH et al. Computation and parameterizations of the nonlinear energy transfer in a gravity wave spectrum. Part II : Parameterizations of the nonlinear energy transfer for application in wave models. Journal of Physical Oceangraphy, 1985, 15(11) : 1378-1391.

[14] Phillips OM. On the generation of waves by turbulent wind. Journal of Fluid Mechanics, 1957, 2(5) : 417-445.

[15] Miles JW. Hamiltonian formulations for surface waves. Applied Scientific Research, 1981, 37(1/2) : 103-110.

[16] Battjes JA, Stive MJF. Calibration and verification of a dissipation model for random breaking waves. Journal of Geophysical Research, 1985, 90( C5) : 9159-9167.

[17] Eldeberky Y. Nonlinear transformation of wave spectra in the nearshore zone[Dissertation]. Netherlands: Delft University of Technology, 1996.

[18] Eldeberky Y, Battjes JA. Parameterization of triad interactions in wave energy models. Gdansk, Poland: Proceeding Coastal Dynamics Conference, 1995: 140-148.

[19] 许遐祯，陶蓉茵，赵巧华等. 大型浅水湖泊太湖波浪特征及其对风场的敏感性分析. 湖泊科学, 2013, 25(1): 5564. DOI 10. 18307/2013. 0108.

[20] 曹 勇, 孙从军, 高阳俊等. 淀山湖水域风浪要素计算研究. 长江流域资源与环境, 2011, 20(Z1): 39-43.

[21] Jackson HO, Starrett WC. Turbidity and sedimentation at Lake Chautauqua, lllinois. Journal of Wildlife Management, 1959, 23: 157-168.

[22] Hamilton DP, Mitchell SF. An empirical model for sediment resuspension in shallow lakes. Hydrobiologia, 1996,317 (3) : 209-220.

[23] 李一平, 逢 勇, 李 勇. 水动力作用下太湖底泥的再悬浮通量. 水利学报, 2007, 38(5): 558-564.

[24] 逢 勇, 李一平, 颜润润等. 内外源共同作用对太湖营养盐贡献量研究. 水利学报, 2008, 39(9): 1051-1059.

[25] 王 震, 邹 华, 杨桂军等. 太湖叶绿素 a 的时空分布特征及其与环境因子的相关关系. 湖泊科学, 2014, 26(4) : 567-575. DOI 10. 18307/2014. 0411.

[26] 李英杰, 胡小贞, 胡社荣等. 草、藻型湖泊水体生态及理化特性的实验对比. 生态环境学报, 2009, 18 (5): 1649-1654.

[27] 李一平, 逢 勇, 刘兴平. 太湖湖流对波浪的影响机制研究. 水利学报, 2007, 38(S1) : 303-308.

[28] Lind OT, Davaloslind LO, Chrzanowski TH et al. Inorganic turbidity and the failure of fishery models. Internationale Revue der Gesamten Hydrobiologie, 1994, 79(1): 7-16.

[29] Hofmann H, Lorke A, Peeters F. The relative importance of wind and ship waves in the littoral zone of a large lake. Limnology and Oceanography, 2008, 53(1): 368-380.

[30] 沈 吉, 袁和忠, 刘恩峰等. 太湖表层沉积物的空间分布与层序特征分析. 科学通报, 2010, 55(36): 3516-3524. 